\title{
Quando o Estado é o perpetrador da violência: Uma análise das vitimizações ocasionadas pela Polícia Militar ${ }^{1}$
}

Ludmila Mendonça Lopes Ribeiro² Valéria Cristina Oliveira ${ }^{3}$

Resumo: Nas últimas décadas, o Brasil tem sido foco de diversos estudos internacionais que procuram mensurar a violência perpetrada pelas organizações policiais e relacioná-la com o grau de institucionalização da democracia. Esse trabalho procura avançar nesta discussão, ao apresentar os dados referentes às vitimizações por agressões verbais e físicas ocasionadas pela Polícia Militar vis-àvis as ocasionadas por civis. A partir deste quadro, pretende-se questionar se a democracia que tem se institucionalizado no Brasil é, em essência, violenta; porquanto tanto os cidadãos como as instituições estatais lançam mão de ações violentas em suas relações cotidianas.

Palavras-chave: Estado, polícia militar, violência.

\begin{abstract}
In recent decades, Brazil has been the focus of many international studies that seek to measure the violence perpetrated by police organizations and relate it to the degree of institutionalization of democracy. This work seeks to advance this discussion, by presenting the data related to victimization by verbal and physical aggression caused as such civilian as military polices corps. From this framework, we intend to question whether democracy that has been institutionalized in Brazil
\end{abstract}

\footnotetext{
${ }^{1}$ Trabalho desenvolvido com o apoio da Universidade Federal de Minas Gerais, a partir dos recursos do Edital 12/2011 (Auxílio à Pesquisa de Doutores Recém- contratados) da PróReitoria de Pesquisa (PRPq).

2 Professora adjunta do Departamento de Sociologia e Antropologia (SOA) e pesquisadora do Centro de Estudos de Criminalidade e Segurança Pública (CRISP), ambos da Universidade Federal de Minas Gerais (UFMG). Email para contato: ludmila.ribeiro@crisp.ufmg.br

${ }^{3}$ Doutoranda em sociologia pelo Departamento de Sociologia e Antropologia (SOA) e pesquisadora do Centro de Estudos de Criminalidade e Segurança Pública (CRISP), ambos da Universidade Federal de Minas Gerais (UFMG). Email para contato:

valeria@crisp.ufmg.br
}

Latitude, Vol. 7, no 2, pp. 219-243, 2013

DOI: https://doi.org/10.28998/2179-5428.20130211 
Quando o Estado é o perpetrador da violência: Uma análise das vitimizações ocasionadas pela Polícia Militar

is essentially violent; because both citizens and state institutions resort to violent actions in their daily life.

Key-words: State, military police, violence.

\section{Introdução}

Às vésperas da Copa do Mundo FIFA de 2014, o Brasil se conforma em destino de milhares de fanáticos por futebol, jornalistas e interessados em conhecer melhor a dinâmica deste país que integra o grupo das principais economias emergentes. Todavia, um dos problemas que ainda parece bloquear o interesse pelo país é a violência cotidiana, em especial, a praticada pela polícia (French, 2013). Esse quadro qualificaria a sociedade brasileira de incivil, em razão da emergência da democracia como regime, apesar da continuidade da violação de direitos humanos pelas instituições estatais.

Diagnósticos como o delineados por Holston e Caldeira (1998), que qualificam a democracia brasileira como disjuntiva, enfatizam que a violência perpetrada pelas organizações policiais seria um indicativo indelével da incapacidade dos cidadãos brasileiros em concluírem a transição do autoritarismo (1964-1985) para a democracia (1986-hoje). A grande diferença existente entre os dois regimes de governo é o fato de que, na democracia, os direitos civis, políticos e sociais existiriam do ponto de vista formal e substantivo, cabendo às instituições estatais garantirem a sua inviolabilidade.

Logo, a vitimização de um cidadão pela organização policial seria um obstáculo à consolidação democrática porque a instituição criada para garantir a vida, a integridade física, a liberdade e a propriedade estaria violando os pressupostos que justificam a sua existência. Por isso, os analistas políticos tendem a enfatizar o aparente paradoxo brasileiro, já que a institucionalização da democracia nessa localidade se fez vis-à-vis o aumento da vitimização por crime, incluindo-se nessa categoria os delitos praticados pela polícia (Peralva, 2000).

Para se ter uma ideia deste cenário, nos anos de 2010 e 2011, em média, 10\% do total de homicídios dolosos registrados no Estado de São Paulo foram praticados pela Polícia Militar (FBSP, 2013). No Rio de Janeiro, esse percentual chega a $15 \%$ do total de homicídios dolosos, sendo que, desde a década de 1990, esse é o patamar mais baixo já alcançado pela violência letal policial (Cano, 2012). Em razão da magnitude dos registros observados em todo país nos últimos 25 anos, o Brasil ocupa uma das primeiras posições no ranking da violência letal policial mundial (HRW, 2009).

Esses números podem ser muito maiores em razão do não registro adequado das mortes ocasionadas pelas polícias brasileiras, que muitas vezes são somadas com os homicídios praticados por civis, ou encobertas em categorias pouco elucidativas. De acordo com o levantamento realizado pelo FBSP (2013), as agências policiais tendem a utilizar oito denominações distintas para classificar esse tipo de ocorrência, entre as quais se encontram resistência seguida de morte, autos de resistência e morte em confronto. 
Do ponto de vista analítico, a Polícia Militar seria a mais susceptível a vitimizar os cidadãos em razão de sua atribuição constitucional de policiamento ostensivo. Como os policiais de linha de frente estariam distribuídos pela cidade para prevenir a ocorrência do crime, sem possibilidade de supervisão direta constante, existiria uma maior possibilidade de eles ultrapassarem os ditames legais e violentarem a integridade física ou patrimonial dos transeuntes, sem que essa conduta chegue ao conhecimento dos supervisores.

Por outro lado, a violência praticada pela Polícia Militar no exercício de sua atividade de policiamento ostensivo tem maiores chances de permanecer impune em razão da diminuta probabilidade de as vítimas registrarem o ocorrido em uma delegacia de polícia. Estudos que procuram desvelar esse fenômeno sugerem que as vítimas de agressão verbal e física não comunicam o ocorrido às autoridades competentes, quando o perpetrador da violência é um policial, por temerem represálias (Mitchells e Wood, 1999), da mesma forma que não acionam as instituições de justiça (como o Ministério Público) pelo mesmo motivo (Ribeiro e Machado, 2014). Com isso, a única violência policial que possui visibilidade na sociedade brasileira é a letal, pois que as de menor potencial ofensivo permanecem razoavelmente desconhecidas em razão de sua não notificação às autoridades competentes (Beato, 2012).

Grande parte da violência praticada pelas organizações policiais militares somente pode ser mensurada a partir do uso de surveys de vitimização; que são pesquisas nas quais uma amostra de indivíduos é indagada quanto ao fato de terem sido (ou não) vítimas dum crime no último ano, sobre quem era o agente da violência e o tipo de encaminhamento institucional dado a esse fato. Em estudos dessa natureza, procura-se mensurar, em última instância, a quantidade de crimes ocorridos que não foi comunicada à polícia, as razões que suscitaram esse fato e, ainda, o perfil dos delitos que possuem maiores taxas de subnotificação (Lima e Borges, 2014)

As pesquisas de vitimização são as melhores fontes para mapeamento da violência praticada pelas organizações policiais por se basearem nas informações coletadas a partir de pesquisas domiciliares e não nos registros administrativos, que são produzidos pela própria polícia. Esse tipo de fonte permite uma melhor compreensão das regularidades da vitimização; tanto do ponto de vista da natureza da infração praticada por esses agentes, como também das características socioeconômicas das vítimas preferenciais.

O presente trabalho procura descrever o aparente paradoxo brasileiro a partir da apreciação das informações coletadas na 1a. Pesquisa Nacional de Vitimização - PNV (Datafolha / CRISP, 2012), no que diz respeito à vitimização por agressão verbal e física, de acordo com o agente perpetrador (cidadãos comuns e Polícia Militar). Para a realização desse empreendimento, este estudo encontra-se dividido em três seções, além desta introdução.

Latitude, Vol. 7, no 2, pp. 219-243, 2013. 
Quando o Estado é o perpetrador da violência: Uma análise das vitimizações ocasionadas pela Polícia Militar

Na primeira, os conceitos de democracia e violência e de democracia violenta são escrutinados com o objetivo de se examinar qual a possibilidade de eles explicarem as taxas de vitimização por agressão verbal e física encontradas no Brasil. Em seguida, os dados da 1a. Pesquisa Nacional de Vitimização (PNV) são apresentados, destacando-se os tipos de ilícitos praticados pela PM que foram mensurados neste survey, bem como os estados que concentram os níveis mais elevados deste tipo de violência e os perfis preferenciais de vítimas. Por fim, são apresentadas as conclusões, que procuram conjugar o arcabouço teórico da primeira parte do texto com o analítico da segunda.

\section{As conexões entre democracia e violência no cenário brasileiro: uma revisão da}

\section{literatura}

O ponto de partida dessa discussão é a obra de Angelina Peralva, "Democracia e Violência: o paradoxo brasileiro." Publicado em 2000, este livro apontava para a importância de uma crítica do caminho percorrido pelo brasileiro no que diz respeito à incidência da violência letal. Isso porque a transição autoritarismo - democracia não significou redução dos crimes de sangue, praticados como forma de resolução interpessoal de conflitos.

O fim do autoritarismo significou o encerramento da violência política e o início de um outro tipo: a criminal, que inclui homicídios, assaltos, sequestros, corrupção, dentre outros. Essa alteração no padrão de incidência de casos de violência é esperada porque, em um regime autoritário, as garantias constitucionais estão suspensas e, por isso, torna-se muitas vezes inviável trazer para a esfera pública determinados crimes, partindo-se para a estratégia de se "fazer justiça com as próprias mãos". As próprias instituições estatais deixam de ter a função de servir aos cidadãos para se consubstanciarem enquanto porta-voz do regime e, por isso, a possibilidade de violentar um indivíduo qualquer é muito mais eminente do que em uma democracia.

Uma vez mudadas as regras do jogo, a importância da garantia aos direitos dos cidadãos passa a se consubstanciar no cerne das preocupações das agências públicas. A esperança era que a transição autoritarismo / democracia colocasse, de maneira quase automática, a redução da quantidade de crimes violentos em geral e homicídios em especial (Cano, 2006).

Contudo, ao contrário do constatado historicamente em outros continentes, “o pós-autoritarismo na América Latina significou a continuidade da violência, porém de uma forma distinta. Insegurança é um dos maiores fatores de pressão sobre a agenda pública. Na maioria dos países, os níveis de crime são assustadores" (Bonner, 2014, p.261). No Brasil, a transição autoritarismo democracia não implicou em um maior controle da letalidade das forças policiais e muito menos a uma judicialização dos conflitos e, por conseguinte, redução da violência letal interpessoal.

Como indicativo desse argumento, basta analisar os dados de homicídio doloso para o período 1980 - 2012, os quais denotam uma tendência contrária ao 
esperado. Em 32 anos a taxa saiu de 11 casos para cada 100.000 habitantes para 26 casos para cada 100.000 habitantes, o que significa um crescimento de mais de $100 \%$ (Gráfico 01).

Gráfico 1 - Taxa de Homicídios para cada grupo de 100.000 habitantes Brasil (1980 - 2012)

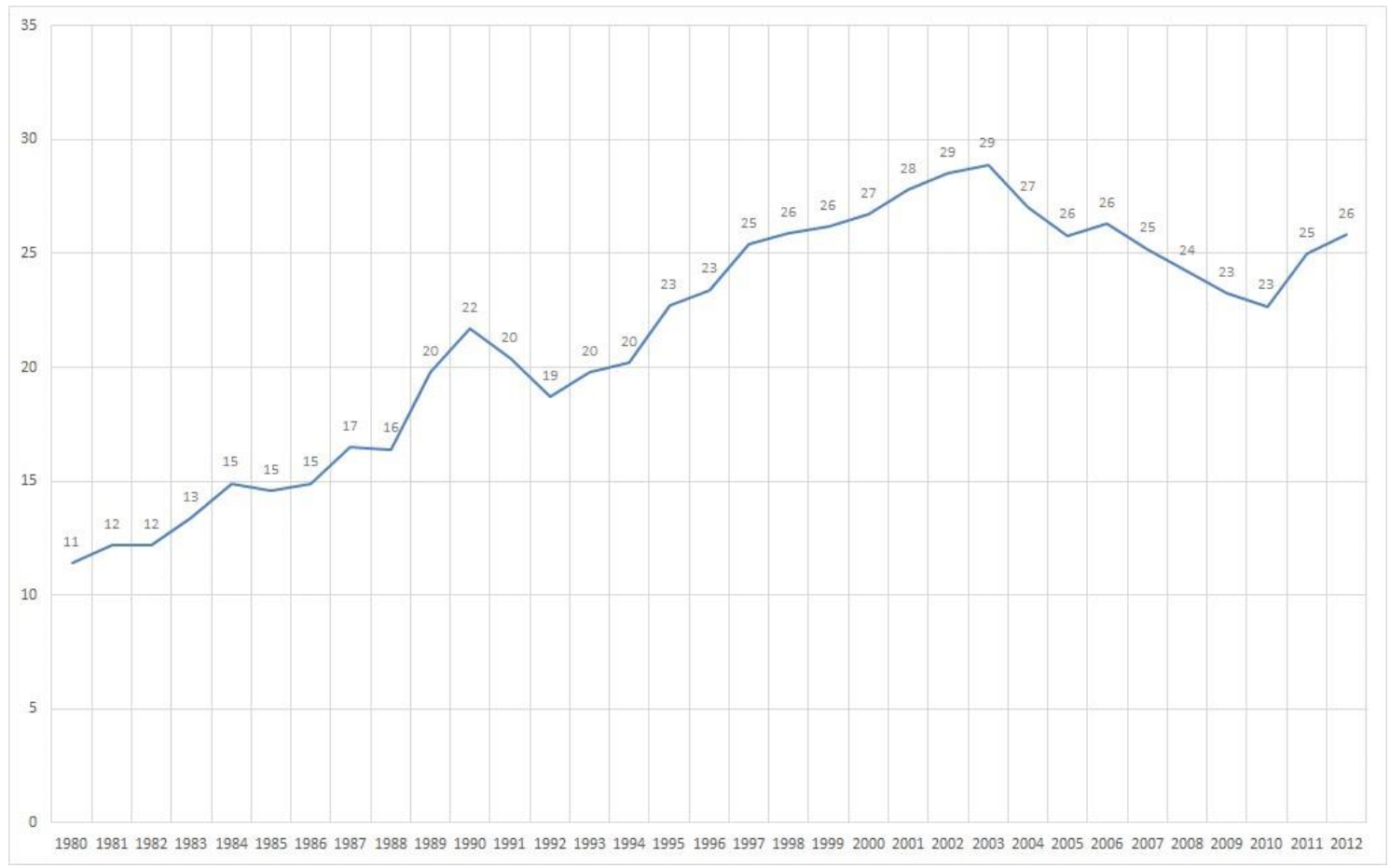

Fonte: SIM/DATASUS - Mapa da Violência no Brasil (2013)

Esse aparente paradoxo brasileiro pode ser entendido como a combinação da disseminação de um padrão de uma sociabilidade violenta por parte de uma determinada parcela da população (Machado da Silva, 2008) e pelas instituições estatais, que longe de preservarem a ordem seriam responsáveis por uma parcela das mortes violentas (Beato, 2012), conformando o que Arias e Goldstein (2010) denominam de democracia violenta.

A sociabilidade violenta seria um fenômeno característico de algumas áreas das metrópoles brasileiras nas quais as ações dos residentes são coordenadas quase exclusivamente por referência a escalas de força física. Nesses espaços, "os atores não compartilham valores comuns que poderiam regular o uso da violência na realização dos seus desejos, limitando-a, a condição de um meio entre outros para a obtenção de fins" (Machado da Silva, 2008, p. 21).

O único elemento levado em consideração por parte dos atores envolvidos em redes de sociabilidade violenta é a capacidade de resistência que os outros podem opor para impedir a realização dos seus desejos mais imediatos. “Na 
Quando o Estado é o perpetrador da violência: Uma análise das vitimizações ocasionadas pela Polícia Militar

sociabilidade violenta, quem tem mais força usa os outros, assim como artefatos para impor a sua vontade, sem considerar princípios éticos, deveres morais, afetos, etc". Isso faz com que os moradores comuns das favelas sejam duplamente dominados: "na ordem social dominante, compõem os estratos inferiores da estrutura social; na "sociabilidade violenta", são obrigados a se submeter aos traficantes" (Machado da Silva, 2008, p. 22).

Para sobreviver, os cidadãos devem saber distinguir as mudanças de comando dos traficantes rivais que disputam os domínios de uma dada organização criminosa; as interfaces entre os "bandidos" e a polícia; ou as regras das milícias que se alastram pelas principais cidades brasileiras. ${ }^{4}$ Precisam também de ser capazes de perceber as mudanças de comando da própria organização policial, que podem definir sobremaneira as formas de interação das organizações estatais com as franjas da sociedade.

Assim, seria interessante indagar qual foi o espaço ocupado pela própria democracia, pois é difícil conjugar a sua existência com a administração violenta de conflitos. Peralva (2000) problematiza o aumento das violações de direitos humanos vis-à-vis a expansão legal dos direitos civis, políticos e sociais, em consonância com a maior disponibilidade de informações.

O impasse colocado pela democracia - capacidade de institucionalizar agências que além de garantirem a não violação de direitos humanos seriam responsáveis pelo adequado processamento desses incidentes - parece ter fracassado no caso brasileiro. O país passou do autoritarismo para a democracia, sem que a preservação da vida face a não recorrência à violência como mecanismo de resolução interpessoal de conflitos deixasse de existir, institucionalizando o paradoxo brasileiro.

Para Arias e Goldstein (2010), avançar nessa argumentação significa remeter à polissemia do termo democracia. Partindo do pressuposto de que este conceito deve ser utilizado para identificar determinadas qualidades procedimentais do regime político e algumas dimensões substantivas, como a existência da Rule of Law, nas dimensões de inclusão sócio-política, justiça pública, e transparência; as taxas de violência se configuram como um indicador do grau de comprometimento do regime em uma dada localidade.

Seguindo essa argumentação, o Brasil seria classificado como pouco democrático porque, desde a promulgação da Constituição Federal, em 1988, dada a contradição existente entre os ideais de paz e respeito aos direitos e a realidade de insegurança e violência (Gráfico 01). Esse panorama reforçaria a qualificação da democracia brasileira como imperfeita, iliberal, incompleta e disjuntiva, já que os

\footnotetext{
${ }^{4}$ Segundo reportagem do Jornal "O Globo" de 30 de outubro de 2011, as milícias não apenas se alastraram pela cidade do Rio de Janeiro, como já se fazem presentes em 11 estados brasileiros, não sendo mais, portanto, uma característica específica da realidade do Rio de Janeiro - http://oglobo.globo.com/pais/mat/2011/10/29/milicias-se-alastramporpelo-menos-11-estados-925699563.asp, acesso em 30/11/2011.
} 
dispositivos legais não são capazes de se traduzir em substância, especialmente, no direito mais essencial: a vida (Holston e Caldeira, 1998).

O problema mais deletério de democracias com qualificativos reside na institucionalização da cidadania de baixa intensidade, fazendo com que determinados direitos sejam vistos como liberalidades dos governantes e, pior, inviabilizando o questionamento de políticas sociais que longe de reduzirem a assimetria dos indivíduos contribuem para o seu reforço. No Brasil, essa paisagem é especialmente peculiar em razão de os direitos civis serem suprimidos pelas organizações que deveriam ser responsáveis por seu zelo, fazendo com que um número bastante substantivo de mortes aconteça em razão da incapacidade dos indivíduos em acessar o Estado ou em receber dele o mais fatal dos julgamentos: a condenação à morte sem o devido processo legal (O'Donnel, 2004). ${ }^{5}$

Forma inovadora de abordar essa relação é a proposta por Arias e Goldstein (2010) que compreendem a violência como uma parte da estrutura democrática que tem lugar na América Latina. Para eles, a democracia que se desenvolve na região é violenta porque todos os agentes (estatais e não estatais) se utilizam deste mecanismo para a coordenação de suas ações, dando ensejo a um pluralismo de violências sem correspondente em outros continentes. A origem de tal fenômeno estaria no autoritarismo que permeia a história do continente, criando uma espécie de dependência de trajetória que tem no uso da violência sua principal forma de administração de controvérsias, exercício do poder e estruturação das diversas formas de dominação.

Historicamente, no processo de construção do que seria uma democracia neoliberal, os estados latino-americanos aumentaram a desigualdade, diminuíram os serviços sociais e o desemprego, mas privatizaram a segurança de distintas maneiras. Na ausência de outros mecanismos de coordenação, a violência se conformou no instrumento mais comum para a administração da ordem, se tornando de uso mais recorrente, tendo como correlato o seu uso desorganizado pelas distintas instituições - públicas e privadas - ao invés de sua concentração legítima no âmbito das organizações policiais (Bonner, 2014, p. 263).

A principal consequência da democracia violenta é a sedimentação de uma visão que equivale a estruturação da democracia (procedimental e substantiva) ao uso recorrente da violência, sem qualquer distinção quanto à legitimidade do agente que a maneja (Arias e Goldstein, 2010). Pelo contrário. O uso da violência por agentes públicos e privados se torna justificável para coordenar as externalidades de agência da própria democracia, especialmente em áreas onde a exclusão dos direitos de cidadania se fazem mais recorrentes; uma vez que o

\footnotetext{
${ }^{5}$ Nesse sentido, vale a leitura de Machado da Silva (2008) sobre a disseminação da sociabilidade violenta entre os jovens e o uso da "morte" enquanto mecanismo de resolução interpessoal de conflitos e a leitura de Misse (2010) sobre o fato de a polícia ser o juiz antes do próprio processo legal a partir da autorização que essa organização acredita possuir para "matar" os bandidos.
} 
Quando o Estado é o perpetrador da violência: Uma análise das vitimizações ocasionadas pela Polícia Militar

Estado recuou das provisões de bem estar social e reforçou a repressão, ou cedeu o controle do território a outros criminosos (Bonner, 2014, p. 263).

Portanto, conectando os conceitos de sociabilidade violenta (Machado da Silva, 2008) e democracia violenta (Arias e Goldstein, 2010) compreende-se a violência como um fenômeno plural e dialético, que assume múltiplas formas, determinando de inúmeras maneiras a vida cotidiana dos indivíduos e os próprios mecanismos de governança democrática. As violências - interpessoal e policial passam a ser entendidas como as ossaturas da democracia latino-americana e não uma consequência da desorganização, falência ou incapacidade dos aparelhos do Estado em reprimi-la. Longe de ser algo que erode a confiança dos cidadãos na democracia ou em suas instituições, a violência se conforma em um recurso legítimo, do qual os indivíduos lançam mão historicamente para criar e recriar a experiência democrática a partir dos seus próprios paradigmas. Essa nova forma de compreender o fenômeno demonstra porque as abordagens tradicionais do significado e do desempenho da democracia são limitadas para explicar porque, embora o autoritarismo tenha se extinguido, os homicídios crescem continuamente, tanto em sua modalidade dolosa quanto na categoria autos de resistência. ${ }^{6}$

A proposta deste trabalho é avançar nessa discussão a partir do escrutínio dos padrões de agressão verbal e física, sublinhando as regularidades existentes entre as vitimizações praticadas pela Polícia Militar e por civis em geral. Se o argumento da democracia violenta estiver correto, o recurso à agressão verbal e física será uma prática disseminada entre os cidadãos e refletida no padrão de operação da Polícia Militar. Se o argumento do paradoxo brasileiro estiver correto, o recurso à agressão verbal e física será uma característica da ação da Polícia Militar, herdada do período autoritário e não transformada com a mudança do regime.

\section{A violência nossa de cada dia: uma análise das agressões verbais e físicas}

Nesta seção serão apresentados os percentuais de vítimas de agressão verbal e agressão física de acordo com o perpetrador do delito - se um indivíduo qualquer ou um policial militar. Com isso, o recurso à violência seria algo que permeia as relações entre os indivíduos como um todo, em detrimento de modalidades de violência que são mais características à relação entre polícia e cidadão.

Desde o século passado, diagnósticos acadêmicos têm colocado em questão se os registros administrativos oriundos dos crimes contabilizados pelas polícias (militar, com atividade ostensiva, e civil, com atividade judicial) seriam as melhores fontes para a realização de uma contabilidade oficial de crimes (Coelho, 1980). Diferentemente dos registros oficiais, organizados prioritariamente para fins de gerenciamento do trabalho das instituições do sistema de justiça criminal, os surveys de vitimização são um instrumento de pesquisa elaborado com

\footnotetext{
${ }^{6}$ Para uma discussão sobre o significado de autos de resistência, ver Lemgruber (2004). 
metodologia especificamente voltada para a mensuração das experiências de vitimização criminal da população pesquisada (Lima e Borges, 2014). Isso faz com que os enquetes desta natureza consigam revelar, com considerável dose de confiabilidade, as taxas de crimes que não se convertem em registros policiais e não chegam ao conhecimento de gestores públicos ou pesquisadores. Comparando as duas fontes de informação (oficial e vitimização) é possível constatar que entre $25 \%$ e $30 \%$ dos incidentes graves, como roubo, chega ao conhecimento das autoridades (Ministério da Justiça, 2013).

O presente estudo utilizará os dados da primeira Pesquisa Nacional de Vitimização (PNV), realizada pelo Ministério da Justiça. A fim de se criar uma amostra com representatividade nacional, foram selecionados 7.000 setores censitários, 70.000 domicílios nestes setores, e em cada domicílio pelo menos um morador. A partir da realização de 78.000 entrevistas ao longo dos anos de 2011 e 2012, foi possível coletar informações que apresentam um panorama nacional da situação da vitimização por crime, sentimento de insegurança e avaliação do trabalho policial.

A partir da análise da base de dados resultantes da PNV (2012), pretendese delinear os padrões de vitimização por agressão verbal e física experimentados pela população brasileira. Em seguida, procurar-se-á descrever se o recurso a essas modalidades de violência é algo que permeia as relações sociais entre todos os indivíduos ou se algo bastante característico à interação entre polícia e sociedade. Afinal, a ideia de democracia violenta apenas faz sentido se as modalidades de violência acionadas pelos agentes do Estado forem as mesmas utilizadas pelos cidadãos em suas atividades rotineiras.

As agressões verbais e físicas foram escolhidas como base empírica para o trabalho em razão do seu menor potencial ofensivo e, por isso, a sua menor visibilidade quando da análise da criminalidade e da violência no país, dado que esses estudos levam tão-somente os casos de homicídio doloso em consideração. A ideia aqui é perceber como agressões menores e, por isso, negligenciadas pelos analistas, se fazem presentes no cotidiano da população em geral e nos seus encontros com as organizações policiais em especial.

Para facilitar a interpretação dos resultados essa seção será subdivida em duas, sendo que, na primeira, serão apresentados os dados referentes às agressões verbais, seguidos pelos relativos às agressões físicas.

\section{As agressões verbais}

A agressão verbal é aquela conduta que tem como objetivo lesionar um outro indivíduo diretamente, a partir do uso de palavras de cunho vexatório ou de xingamento que têm como propósito causar uma lesão psicológica em outro indivíduo.

Segundo os dados da PNV (2012), entre os anos de 2011 e 2012, 11,1\% dos brasileiros foram vítimas de agressão verbal. Quando indagados especificamente 
Quando o Estado é o perpetrador da violência: Uma análise das vitimizações ocasionadas pela Polícia Militar

sobre a violência praticada pela Polícia Militar, o percentual de entrevistados que respondeu afirmativamente à questão foi um pouco menor: $6,7 \%$. A diferença de $4,4 \%$ entre a vitimização comum (praticada pelos indivíduos em geral) e a vitimização específica (praticada pelos policiais militares) permite supor que a agressão verbal compõe a rotina dos indivíduos, dos grupos e das comunidades e, por isso, acaba por encontrar ressonância no padrão de conduta engendrado por policiais militares.

No intuito de averiguar essa hipótese, foram calculados os percentuais de agressão verbal por estado de acordo com o responsável pela prática de tal ato de violência. A tendência de recurso à agressão verbal por parte da organização policial é tanto maior, quanto menor a probabilidade de ela ser utilizada por um cidadão comum na mesma localidade (Gráfico 2).

Gráfico 2 - Percentual de Vítimas de Agressão Verbal Geral ou Praticada pela Polícia Militar Brasil (2012) 


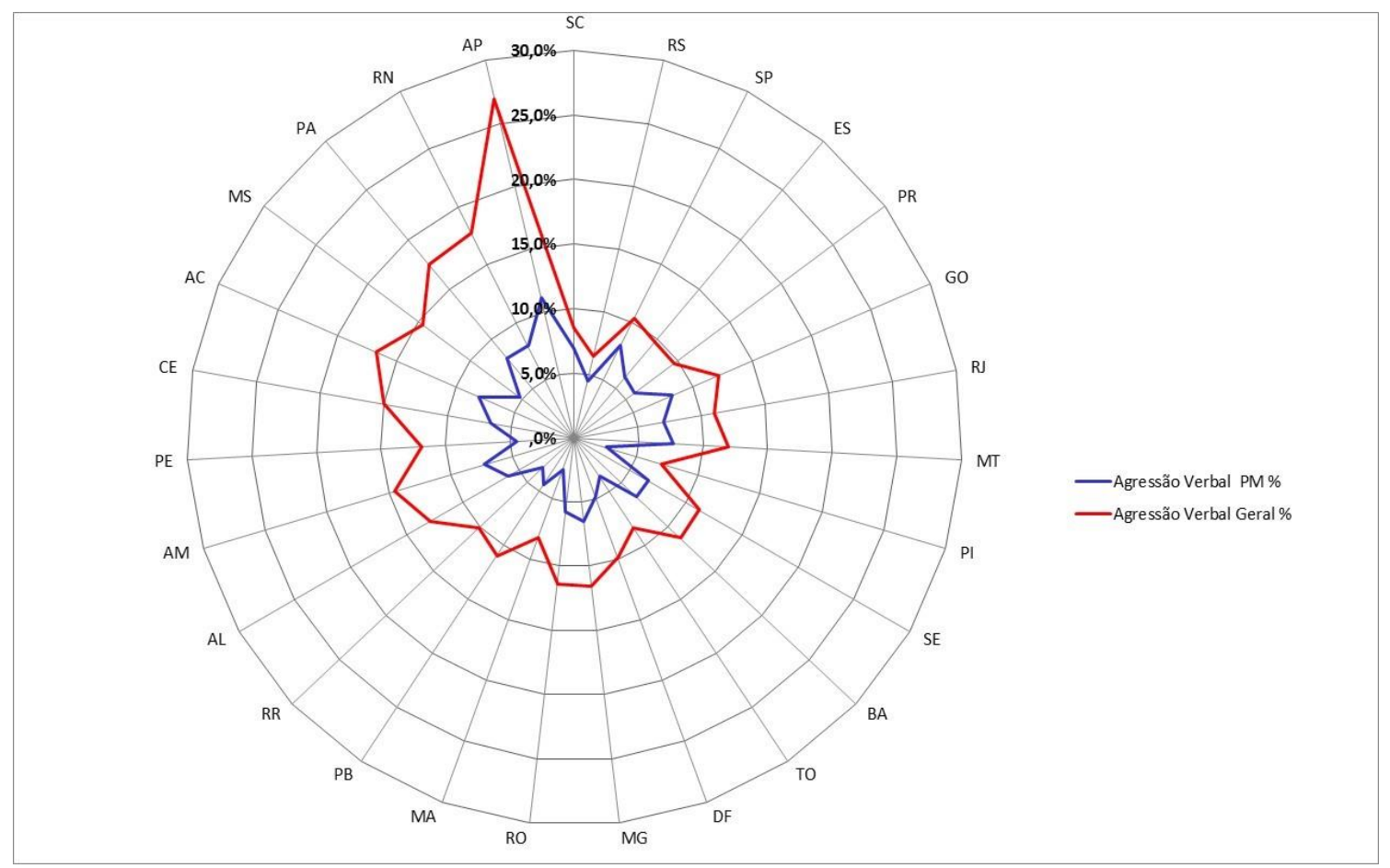

Fonte: Pesquisa Nacional de Vitimização (2012)

O Gráfico 02 indica que a diferença média entre os dois percentuais é de $6 \%$, sendo que a menor diferença se localiza no estado de Santa Catarina $(1,6 \%)$ e a maior diferença se localiza no estado do Amapá (15,8\%). O Mapa 1 reforça essa constatação, demonstrando que os estados com maiores percentuais de agressão verbal entre os indivíduos, grupos e comunidades são aqueles nos quais a Polícia Militar tende a recorrer com maior frequência a esse recurso em suas abordagens.

A região norte do país é um bom exemplo dessa lógica de reflexo da cultura local no modus operandi da Polícia Militar. Essa localidade concentra estados como Pará e Rondônia, que possuem elevada taxa de vítimas de agressão verbal em geral (em torno de 17\%) e de agressão verbal praticada pela Polícia Militar (em torno de $8 \%)$.

Mapa 1 - Percentual de Vitimizações por Agressão Verbal Geral e Agressão Verbal praticada por Policial Militar - Brasil (2012) 
Quando o Estado é o perpetrador da violência: Uma análise das vitimizações ocasionadas pela Polícia Militar

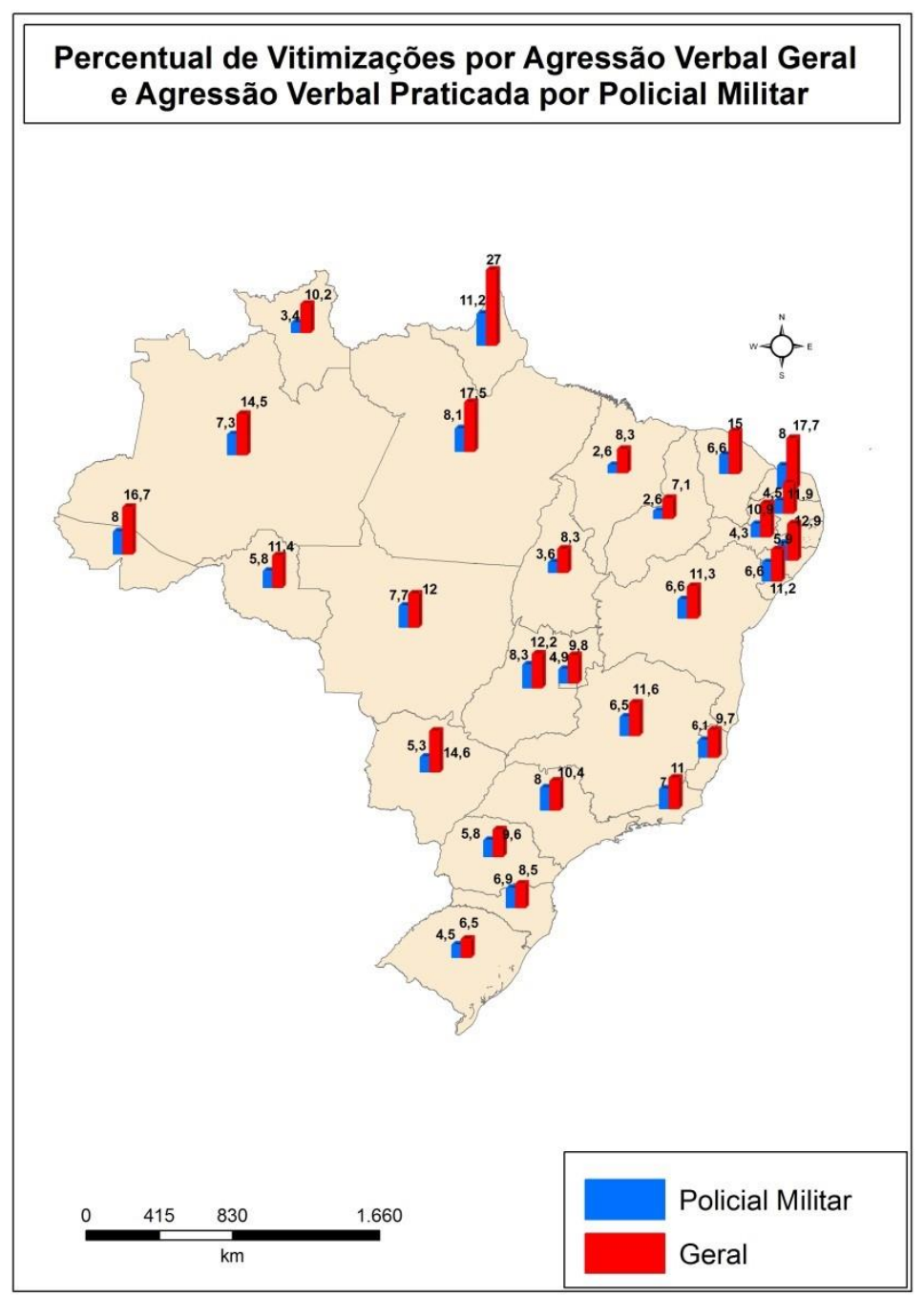

Fonte: Pesquisa Nacional de Vitimização (2012)

Para reforçar o argumento de que o recurso à violência verbal é algo constituinte das relações sociais entre os brasileiros e não algo específico do padrão de operação das organizações policiais, os perfis dos indivíduos que relataram a agressão verbal foram desenhados (Tabela 01).

Como se pode observar, independentemente do agressor, as vítimas de violência verbal são jovens entre 16 e 34 anos. Há igualmente uma presença razoável de vítimas de 35 a 44 anos e baixa presença de idosos (60 anos e mais). Perfil semelhante de vitimização é encontrado quando a cor da pele é levada em consideração: pardos somados com pretos representam quase $50 \%$ entre os que sofrem com a agressão verbal em geral e com a praticada por policiais militares.

Também não encontrou-se diferença entre os percentuais de vítimas na categoria grau de instrução. Ambos os grupos possuem até Ensino Médio completo, sendo bastante expressiva a participação da categoria 10 grau 
incompleto. O mesmo foi observado quando a faixa de renda foi a variável independente, posto que a maioria dos que relataram sofrer com a violência verbal possui renda mensal de até cinco salários mínimos.

Tabela 1 - Perfil das vítimas de agressão verbal, de acordo com o tipo de agressor Brasil (2012)

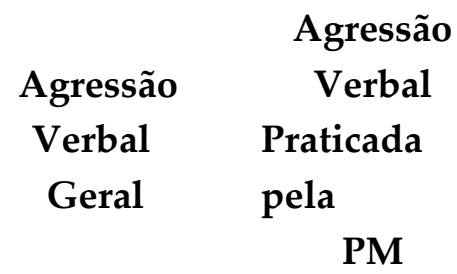

$\mathbf{N} \quad \% \quad \mathbf{N} \quad \%$

\section{Sexo}

Homens

$3756 \quad 43,4 \% \quad 4150 \quad 79,6 \%$

Mulheres

$4890 \quad 56,6 \% \quad 1060 \quad 20,3 \%$

Total

$8646 \quad 100,0 \% \quad 5210 \quad 100,0 \%$

\section{Idade}

16 a 24 anos

$2417 \quad 28,0 \% \quad 1680 \quad 32,2 \%$

25 a 34 anos

$2429 \quad 28,1 \% \quad 1784 \quad 34,2 \%$

35 a 44 anos

$1686 \quad 19,5 \% \quad 946 \quad 18,1 \%$

45 a 59 anos

$1544 \quad 17,9 \% \quad 656 \quad 12,6 \%$

60 anos ou mais

$571 \quad 6,6 \% \quad 144 \quad 2,8 \%$

Total

$8646 \quad 100,0 \% \quad 5210 \quad 100,0 \%$

\section{Cor da pele}

Branco

\begin{tabular}{clcc}
3524 & $40,8 \%$ & 2059 & $39,6 \%$ \\
3732 & $43,2 \%$ & 2212 & $42,5 \%$ \\
1028 & $11,9 \%$ & 735 & $14,1 \%$ \\
354 & $4,1 \%$ & 195 & $3,7 \%$ \\
8638 & $100,0 \%$ & 5200 & $100,0 \%$ \\
\hline
\end{tabular}

Grau de instrução

Sem instrução

$245 \quad 2,8 \% \quad 79 \quad 1,5 \%$

Latitude, Vol. 7, no 2, pp. 219-243, 2013. 
Quando o Estado é o perpetrador da violência: Uma análise das vitimizações ocasionadas pela Polícia Militar

\begin{tabular}{|c|c|c|c|c|}
\hline $\begin{array}{l}\text { Ensino fundamental incompleto (1o. Grau } \\
\text { incompleto) }\end{array}$ & 2194 & $25,4 \%$ & 1178 & $22,6 \%$ \\
\hline $\begin{array}{l}\text { Ensino fundamental completo (1o. Grau } \\
\text { completo) }\end{array}$ & 759 & $8,8 \%$ & 566 & $10,9 \%$ \\
\hline $\begin{array}{l}\text { Ensino médio incompleto (2o. Grau } \\
\text { incompleto) }\end{array}$ & 1369 & $15,8 \%$ & 891 & $17,1 \%$ \\
\hline Ensino médio completo (2o. Grau completo) & 2398 & $27,7 \%$ & 1568 & $30,1 \%$ \\
\hline $\begin{array}{l}\text { Superior incompleto (Universidade / } \\
\text { Faculdade incompleto) }\end{array}$ & 754 & $8,7 \%$ & 424 & $8,1 \%$ \\
\hline $\begin{array}{l}\text { Superior completo (Universidade / } \\
\text { Faculdade completo) }\end{array}$ & 631 & $7,3 \%$ & 393 & $7,5 \%$ \\
\hline Pós-graduação & 293 & $3,4 \%$ & 110 & $2,1 \%$ \\
\hline Total & 8643 & $100,0 \%$ & 5210 & $100,0 \%$ \\
\hline
\end{tabular}

\section{Renda}

Até 1 salário mínimo

$181822,0 \%$

$15,9 \%$

\begin{tabular}{lclcc} 
& & \multicolumn{3}{c}{783} \\
Mais de 1 até 2 salários mínimos & 2422 & $29,3 \%$ & 1504 & $30,6 \%$ \\
Mais de 2 até 3 salários mínimos & 1656 & $20,0 \%$ & 1078 & $21,9 \%$ \\
Mais de 3 até 5 salários mínimos & 1415 & $17,1 \%$ & 921 & $18,7 \%$ \\
Mais de 5 até 10 salários mínimos & 629 & $7,6 \%$ & 417 & $8,5 \%$ \\
Mais de 10 até 15 salários mínimos & 167 & $2,0 \%$ & 102 & $2,1 \%$ \\
Mais de 15 até 20 salários mínimos & 90 & $1,1 \%$ & 52 & $1,1 \%$ \\
Mais de 20 salários mínimos & 82 & $1,0 \%$ & 56 & $1,1 \%$ \\
Total & 8278 & $100,0 \%$ & 4913 & $100,0 \%$ \\
\hline
\end{tabular}

Fonte: Pesquisa Nacional de Vitimização (2012)

Esses dados informam que a violência verbal encontra-se concentrada entre os jovens, pretos e pardos, com baixo grau de instrução e baixa renda; reafirmam as conclusões de pesquisas anteriores sobre as vítimas da violência no Brasil, ${ }^{7}$ o que adverte que entre essa camada da população o recurso à agressão como forma de administração de controvérsias é mais provável do que entre as demais.

Segundo os dados apresentados na Tabela 1, as vítimas de agressão verbal se diferenciam de acordo com o sexo, porquanto os que sofrem com essa violência

\footnotetext{
${ }^{7}$ Para os perfis dos mortos por homicídio doloso, ver Waiselfisz (2013)

Latitude, Vol. 7, no 2, pp. 219-243, 2013.
} 
em geral são, em sua maioria, mulheres (56,5\%) e os atingidos pela ação da Polícia Militar são majoritariamente homens (79,6\%). Enquanto a violência verbal em geral encontra-se mais espraiada entre os sexos, a praticada pela polícia concentra-se entre os indivíduos do sexo masculino.

Esses dados reforçam a ideia de que existe uma espécie de sociabilidade violenta que atinge em especial os jovens, de baixa renda e de baixa escolaridade. Ao contrário do observado nos estudos de violência letal, no caso das agressões verbais, a diferença em termos de vitimizados pela Polícia Militar concentra-se apenas no sexo, já que a maioria desses é homem.

\section{As agressões físicas}

As agressões físicas são aquelas condutas intencionalmente praticadas com o objetivo de causar uma lesão temporária ou permanente em um determinado indivíduo. Em regra, tratam-se de batidas, empurrões ou chutes, bem como lesões provocadas por algum objeto atirado a outrem, além de espancamentos, tentativas de estrangulamento, esfaqueamentos ou tiros cujo resultado não tenha sido a morte do opositor.

Pela própria natureza das condutas classificadas como agressões físicas, constata-se que essa violência gera lesões corporais de maior magnitude do que as agressões verbais. No Estado de Direito, em que a cultura de paz e a integridade física dos indivíduos são colocados como os valores máximos da nação, é de se esperar um recurso menor a esses atos de violência do que o observado no caso dos xingamentos.

De certa maneira, os dados da PNV (2012) confirmam esse pressuposto, já que 2,7\% dos brasileiros relataram terem sido vítimas de uma agressão física ${ }^{8}$ no último ano. Quando indagados especificamente sobre a violência praticada pela Polícia Militar, o percentual de entrevistados que respondeu afirmativamente à questão foi um pouco maior: $4 \%$. A diferença de 1,3\% entre a vitimização específica (praticada pelos policiais militares) e a vitimização comum (praticada pelos indivíduos em geral) é distinta da agressão verbal, quando os delitos policiais eram menores que os em geral. Essa distinção permite supor que a agressão física é muito mais uma característica da ação policial militar do que algo culturalmente espraiado e, por conseguinte, refletido no modus operandi desta organização.

Quando os percentuais por estados são calculados (Gráfico 3), verifica-se que do total de estados brasileiros (27, incluindo-se o distrito federal), 19 apresentam percentuais de vitimização por agressão física pela Polícia Militar maiores do que os percentuais gerais. As localidades com maior percentual de

\footnotetext{
${ }^{8}$ Como vítimas de agressões físicas praticadas por civis foram incluídos os entrevistados que afirmaram que nos últimos 12 meses foram vitimizados por "Batida, empurrão ou chute", "Lesão Provocada por algum objeto que Ihe foi atirado", "Espancamento ou tentativa de estrangulamento" ou "Esfaqueamento ou tiro"
}

Latitude, Vol. 7, no 2, pp. 219-243, 2013. 
Quando o Estado é o perpetrador da violência: Uma análise das vitimizações ocasionadas pela Polícia Militar

pessoas vitimizadas por agressão física são aqueles que apresentam maior quantidade de violentados pela Polícia Militar.

Gráfico 3 - Percentual de Vítimas de Agressão Física Geral ou Praticada pela Polícia

Militar Brasil (2012)

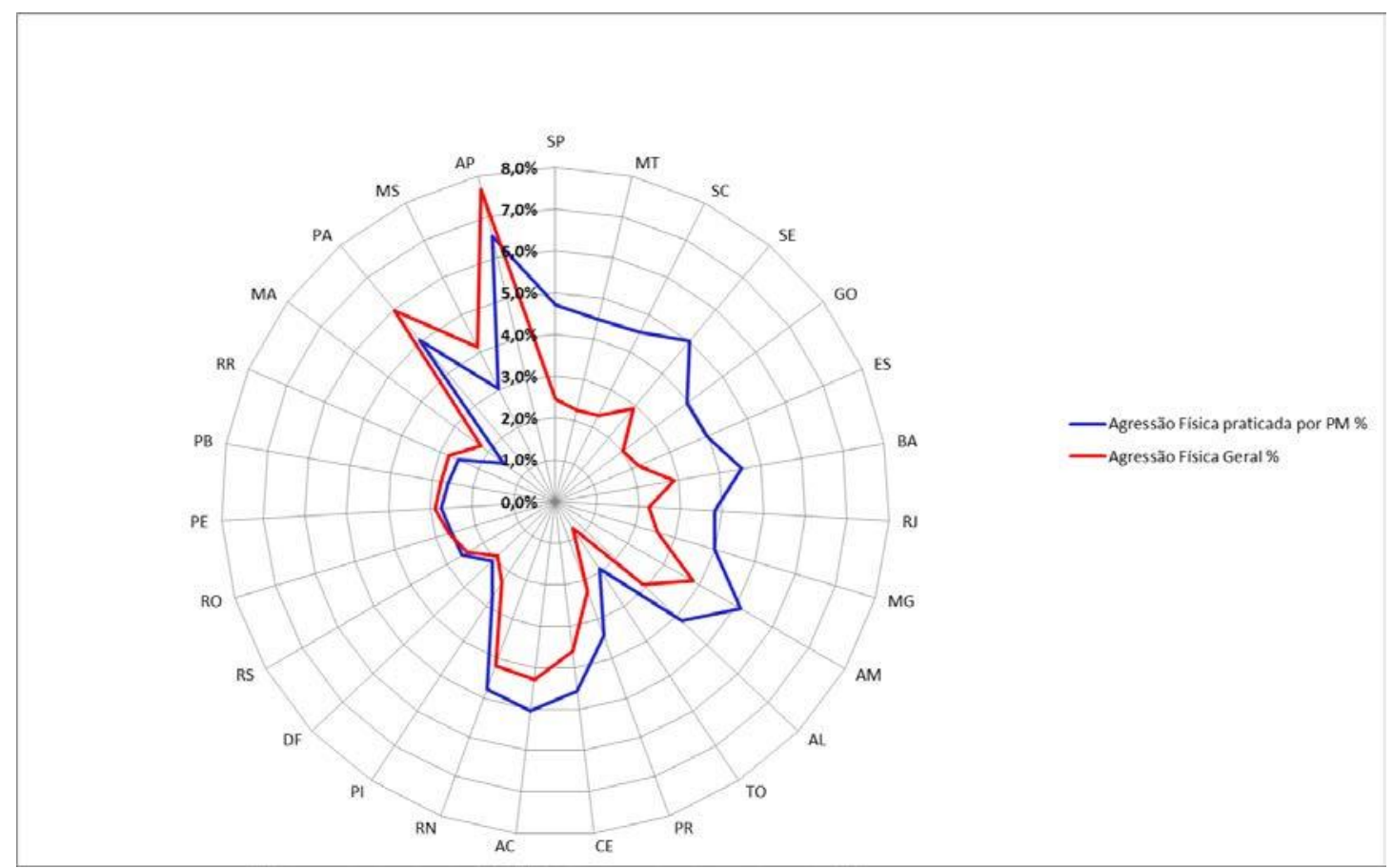

Fonte: Pesquisa Nacional de Vitimização (2012)

Algumas exceções devem ser marcadas. O estado de São Paulo é o caso mais extremo por ter a maior diferença entre os dois percentuais de vitimização, já que $2,5 \%$ dos indivíduos relataram terem sofrido agressão física em geral no último ano, mas 4,7\% afirmaram terem sido vítimas de violência física pela Polícia Militar. O estado do Rio de Janeiro, que tradicionalmente figura ao lado de São Paulo em pesquisas sobre violência policial, apresenta diferença substantiva entre esses dois percentuais: 2,2\% de vítimas de agressão física em geral e 3,8\% por parte da Polícia Militar.

Por outro lado, em que pese a presença de casos excepcionais como Rio de Janeiro e São Paulo, o Mapa 02 confirma que os casos de agressão física praticados pela PM tendem a estar concentrados nos locais em que existe a prevalência de uma grande quantidade de violências dessa natureza, tal como indicam os percentuais do Norte do país. Apesar da existência do uso de violências físicas de maneira mais disseminada pela PM, essa prática encontra lastros culturais na localidade, lembrando que o recurso à violência física por essa instituição é um legado cultural, uma forma de demonstração unívoca da dependência de trajetória e, por isso, difícil de ser descontinuada a partir dos projetos de reforma das organizações policiais. 
Mapa 2 - Percentual de Vitimização por Agressão Física Geral e Agressão Física praticada por Policial Militar - Brasil (2012)

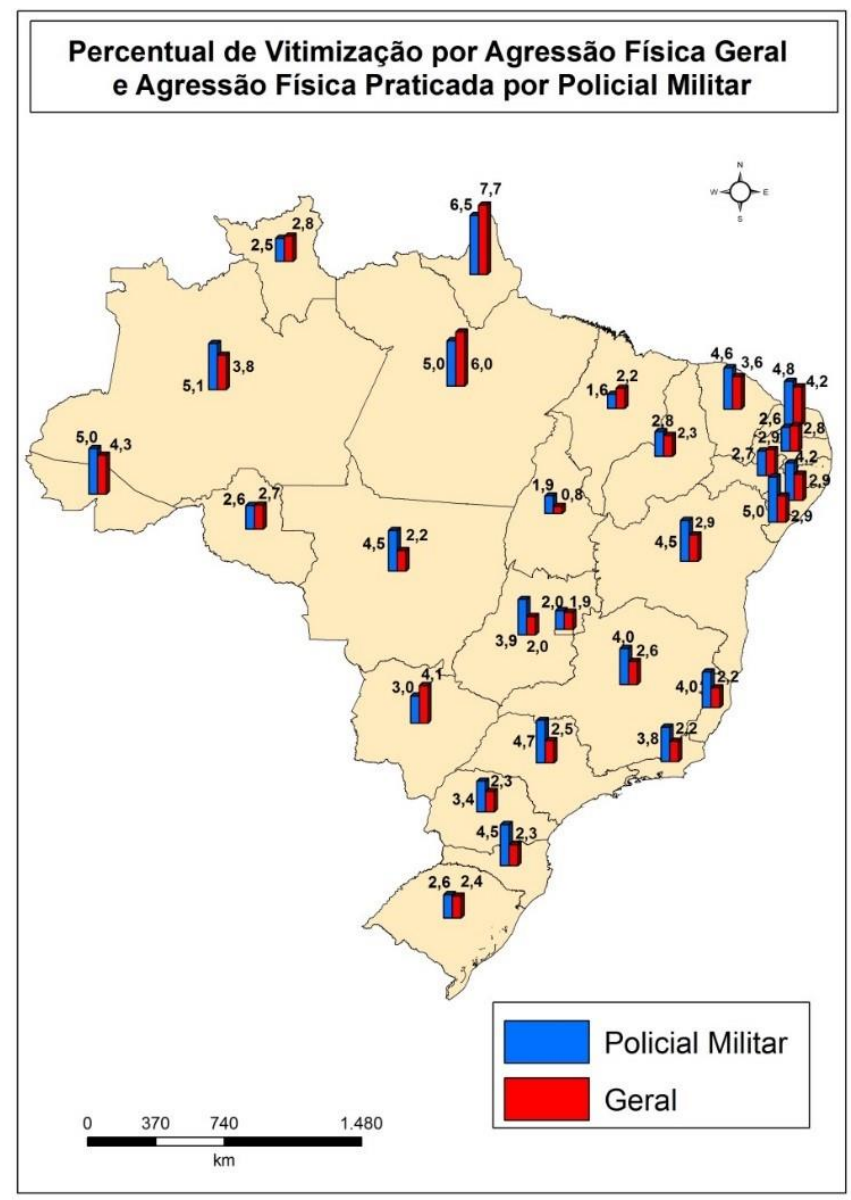

Fonte: Pesquisa Nacional de Vitimização (2012)

Com o objetivo de averiguar em que extensão o recurso à violência física por parte das organizações policiais militares possui especificidades, quando comparada ao uso de agressões físicas pela sociedade em geral, os perfis dos indivíduos que relataram a vitimização por esse tipo de violência foram delineados (Tabela 2).

Tabela 2 - Perfil das vítimas de agressão física, de acordo com o tipo de agressor Brasil (2012) 


\begin{tabular}{lll}
\hline \hline & & Agressão \\
& Agressão & Física \\
Física & Praticada \\
Geral & pela \\
& & PM \\
\cline { 2 - 3 } & & $\mathbf{N} \%$ \\
\hline
\end{tabular}

\section{Sexo}

Homens

$1024 \quad 48,8 \% \quad 2758 \quad 88,1 \%$

Mulheres

$1073 \quad 51,2 \% \quad 373 \quad 11,9 \%$

Total

$2097 \quad 100,0 \% \quad 3131 \quad 100,0 \%$

\section{Faixa etária}

16 a 24 anos

25 a 34 anos

35 a 44 anos

45 a 59 anos

60 anos ou mais

Total

\section{Cor da pele}

Branco

Pardo

Preto

Outro

Total

\section{Grau de instrução}

Sem instrução

Ensino fundamental incompleto (1o. Grau incompleto)

Ensino fundamental completo (1o. Grau

completo)

Ensino médio incompleto (2o. Grau incompleto)

\begin{tabular}{cccc}
866 & $41,3 \%$ & 1078 & $34,4 \%$ \\
550 & $26,2 \%$ & 1149 & $36,7 \%$ \\
336 & $16,0 \%$ & 527 & $16,8 \%$ \\
268 & $12,8 \%$ & 299 & $9,6 \%$ \\
78 & $3,7 \%$ & 77 & $2,5 \%$ \\
2097 & $100,0 \%$ & 3131 & $100,0 \%$ \\
\hline
\end{tabular}

\begin{tabular}{cccc}
854 & $40,8 \%$ & 1170 & $37,4 \%$ \\
896 & $42,8 \%$ & 1316 & $42,1 \%$ \\
254 & $12,1 \%$ & 512 & $16,4 \%$ \\
91 & $4,3 \%$ & 127 & $4,1 \%$ \\
2094 & $100,0 \%$ & 3125 & $100,0 \%$ \\
\hline
\end{tabular}

$\begin{array}{rrrr}59 & 2,8 \% & 71 & 2,3 \% \\ 612 & 29,2 \% & 918 & 29,3 \% \\ 208 & 9,9 \% & 342 & 10,9 \% \\ 388 & 18,5 \% & 570 & 18,2 \%\end{array}$




\begin{tabular}{|c|c|c|c|c|}
\hline Ensino médio completo (2o. Grau completo) & 503 & $24,0 \%$ & 802 & $25,6 \%$ \\
\hline $\begin{array}{l}\text { Superior incompleto (Universidade / } \\
\text { Faculdade incompleto) }\end{array}$ & 202 & $9,7 \%$ & 210 & $6,7 \%$ \\
\hline $\begin{array}{l}\text { Superior completo (Universidade / } \\
\text { Faculdade completo) }\end{array}$ & 84 & $4,0 \%$ & 178 & $5,7 \%$ \\
\hline Pós-graduação & 39 & $1,9 \%$ & 40 & $1,3 \%$ \\
\hline Total & 2096 & $100,0 \%$ & 3131 & $100,0 \%$ \\
\hline
\end{tabular}

\section{Renda}

Até 1 salário mínimo

$\begin{array}{llll}508 & 25,3 \% & 541 & 18,5 \%\end{array}$

Mais de 1 até 2 salários mínimos

$636 \quad 31,6 \% \quad 976 \quad 33,4 \%$

Mais de 2 até 3 salários mínimos

$390 \quad 19,4 \% \quad 608 \quad 20,8 \%$

Mais de 3 até 5 salários mínimos

$286 \quad 14,2 \% \quad 510 \quad 17,4 \%$

Mais de 5 até 10 salários mínimos

$119 \quad 5,9 \% \quad 183 \quad 6,3 \%$

Mais de 10 até 15 salários mínimos

$37 \quad 1,8 \% \quad 48 \quad 1,6 \%$

Mais de 15 até 20 salários mínimos

$8 \quad 0,4 \% \quad 35 \quad 1,2 \%$

Mais de 20 salários mínimos

$25 \quad 1,2 \% \quad 24 \quad 0,8 \%$

Total

$2009100,0 \% \quad 2925 \quad 100,0 \%$

Fonte: Pesquisa Nacional de Vitimização (2012)

As pessoas que foram vítimas de agressão física em geral e pela Polícia Militar apresentam perfil bastante semelhante: a maioria é composta por jovens de até 34 anos, sendo os indivíduos com mais de 60 anos o que possuem menor vitimização por esse tipo de violência. Tal como verificado nos casos de agressão verbal, o recurso a ações violentas parece ser uma prática tanto mais disseminada entre os mais jovens do que entre os mais velhos.

No que se refere à cor da pele, pretos e pardos são maioria entre os agredidos fisicamente, em geral e pela Polícia Militar. Ou seja, quando os afrodescendentes são analisados em conjunto, quanto mais escura é a cor da pele, maior a prevalência da vitimização por agressão física. Esse tipo de violência tende a vitimizar preferencialmente os indivíduos com baixo grau de escolaridade, sendo que $60 \%$ dos agredidos em geral e pela Polícia Militar em especial tinham até o Ensino Médio incompleto. O mesmo ocorre quando a renda é levada em consideração, posto que aproximadamente $70 \%$ dos respondentes que reportaram ter sofrido uma agressão física recebiam até três salários mínimos.

A única característica de perfil das vítimas que não encontra ressonância entre a agressão física praticada em geral e a praticada pela Polícia Militar é o sexo. Enquanto essa violência vitimiza homens e mulheres em percentuais quase equivalentes, quando os policiais militares são os seus perpetradores, os homens 
Quando o Estado é o perpetrador da violência: Uma análise das vitimizações ocasionadas pela Polícia Militar

passam a ser o foco de tal ação, respondendo por $88 \%$ dos casos desta natureza identificados pela PNV. Em outras palavras: se o recurso à agressão física encontrase disseminado de igual maneira entre os sexos, quando os indivíduos em geral são levados em consideração, no caso da Polícia Militar, essa estratégia de ação parece ser acionada quando o agente do Estado se vê diante de um sujeito do sexo masculino.

\section{Interpretando os dados empíricos}

A proposta desta seção foi analisar os perfis de vítimas de agressão verbal e física a partir dos dados da Pesquisa Nacional de Vitimização (PNV, 2012), uma vez que esse sistema de informação apresenta maior confiabilidade do que os registros administrativos operacionalizados pelas organizações policiais a partir das comunicações de vitimização por crime feitas pelos cidadãos.

Os dados apresentados demonstram que o recurso a agressões (verbais e físicas) não pode ser entendido como algo que permeia a cultura brasileira como um todo, pois se assim o fosse os percentuais de vitimização por esse tipo de violência deveriam ser bastante elevados, o que não ocorre. Exclusivamente 11,1\% dos brasileiros relataram ter sofrido violência verbal no último ano e 2,7\% afirmaram terem sido vítimas de agressão física no mesmo período.

Em ambas circunstâncias, essas violências não estão equanimente distribuídas entre os cidadãos, se concentrando em grupos bastante específicos, quais sejam: jovens, de cor da pele escura, com baixa escolaridade e renda de até três salários mínimos. Em última instância, esses dados permitem afirmar que o recurso à agressão como forma de administração de controvérsias é uma característica de determinadas classes sociais.

No entanto, uma diferença entre os dados sumarizados nesse trabalho e os oriundos de outros estudos sobre vitimização por crime deve ser sublinhado: a não incidência diferencial da agressão verbal e física entre os indivíduos do sexo masculino. Pelo contrário. Os dados coletados pela PNV sobre vitimização por agressão em geral reforçam a ideia de que esse tipo de violência é, de fato, uma cultura de jovens pobres e com baixa escolaridade, encontrando-se espraiado entre homens e mulheres em igual proporção.

Outro dado importante de ser mencionado é o referente às diferenças entre as agressões em geral e aquelas praticadas pela Polícia Militar. Os Gráficos 02 e 03 delineiam que a agressão verbal pode ser entendida como uma ação praticada de maneira mais corriqueira na sociedade em geral. Já a agressão física é uma conduta característica das organizações policiais militares, sendo que uma parcela bastante reduzida dos indivíduos em geral dizem terem sido vítimas desse tipo de violência.

Em conjunto, essas constatações advertem que as agressões físicas são formas de violência mais recorrentes entre as Polícias Militares do que entre os indivíduos em geral. No caso das agressões verbais, a relação se inverte, uma vez que as vítimas da ação policial constituem um percentual menor do que as vítimas em geral. Em ambas as situações, os estados com maiores percentuais de vítimas de agressão (física e verbal) pela Polícia Militar tendem a ser aqueles com maior 
percentual de vitimização por essas violências em geral, com especial destaque para a Região Norte (Mapas 1 e 2).

As Tabelas 1 e 2 sugerem que, não obstante a violência por agressão estar concentrada entre as classes sociais mais baixas da população brasileira, quando essa conduta é praticada de maneira geral, ela tende a vitimizar homens e mulheres em igual proporção. Entretanto, quando essas modalidades de violência são praticadas pelas Polícias Militares, elas tendem a alcançar dentro deste estrato somente os homens.

De acordo com os dados reportados nesta seção, as agressões físicas tendem a ser muito mais frequentes quando a controvérsia se dá entre um Policial Militar e um civil, ao contrário do que se observa no caso das agressões verbais. No entanto, quando o agressor é um Policial Militar, a vítima será, preferencialmente, um jovem do sexo masculino, de cor preta ou parda, com baixa escolaridade e renda.

Neste cenário, cumpre indagar qual o significado de tais informações para o argumento que aqui se delineia. Será que o fato de as Polícias Militares serem responsáveis por menos casos de agressão verbal e mais casos de agressão física do que o restante da população demonstra que o Brasil, de fato, vivencia um paradoxo de maior democracia e maior violência? Ou será que esses dados reforçam a ideia de que a democracia que se institucionaliza nessa localidade é em essência violenta? A última seção deste artigo fará um apanhado de tais fenômenos.

\section{A democracia brasileira no Brasil e as violências engendradas pela Polícia Militar: algumas notas finais}

A proposta deste artigo foi a de problematizar as agressões verbais e físicas gerais e as perpetradas pelas organizações policiais militares, dentro do marco conceitual de um Estado Democrático. Desde meados da década de 1980, o Brasil pode ser classificado como uma nação democrática do ponto de vista da existência de direitos civis, políticos e sociais, mas diversas análises contestam esse quadro procedimental, destacando os problemas substantivos deste regime (Holston e Caldeira, 1998).

O que esses especialistas da ciência política vêm destacando desde a reabertura democrática é a dificuldade do Estado e dos próprios cidadãos em transformar esses procedimentos democráticos em algo substantivo. A democracia só pode se institucionalizar como um regime político duradouro se for capaz de se transformar no único sistema de crenças, valores e atitudes vigentes em uma determinada localidade. Logo, a transição do autoritarismo para a democracia deveria significar mudança do paradigma cultural que orienta a ação cotidiana dos indivíduos, já que os padrões de operação das agências estatais nada mais fazem do que ressonar a cultura local ${ }^{9}$.

\footnotetext{
${ }^{9}$ Ver Barros e Prates (1997) sobre o estilo brasileiro de administrar.
} 
Quando o Estado é o perpetrador da violência: Uma análise das vitimizações ocasionadas pela Polícia Militar

De um ponto de vista ideal, democracia representa preocupação com a vida e a integridade de todos os indivíduos. Afinal, qualquer tipo de constrição na igualdade e liberdade dos sujeitos implica em comprometimento no modus operandi do regime democrático. Assim, qualquer tipo de violência deve ser prontamente rechaçada por comprometer o funcionamento do regime e a qualidade da democracia a ser institucionalizada na localidade.

Considerando este arcabouço, dois são os modelos teóricos propostos para o entendimento da democracia brasileira. O primeiro, denominado de paradoxo brasileiro por Peralva (2000), enfatiza que a despeito do fortalecimento das instituições democráticas, a violência aumentou de maneira substantiva e localizada, em especial, nas favelas das grandes cidades. Como possível explicação para esse fenômeno, ter-se-ia a não institucionalização dos valores da democracia entre os cidadãos brasileiros, os quais ainda recorreriam a ações violentas como forma de administração de suas controvérsias. O legado do autoritarismo bloquearia a possibilidade de desenvolvimento do regime desde uma perspectiva culturalista, fazendo com que os procedimentos se descolassem da prática, criando um paradoxo de difícil solução.

O segundo modelo, denominado de democracia violenta por Arias e Goldstein (2010), propõe que a disseminação de ações violentas não pode ser entendida como um indicativo da falência do regime democrático no país, devendo ser a violência compreendida como um dos elementos estruturantes do tipo de democracia que se consolida no Brasil. Trata-se de conduta que subjaz os padrões de interação dos indivíduos e molda a própria forma de operação das instituições estatais. Ao contrário do esperado quando da transição autoritarismodemocracia, essa mudança de regime não foi capaz de alterar a percepção sobre o respeito aos direitos humanos e civis, apesar das profundas transformações operadas no método de escolha dos governantes, em determinadas garantias sociais e, inclusive, nas possibilidades de acesso à justiça. Esse framework enfatiza a importância de se pensar a qualidade da democracia brasileira em uma perspectiva menos institucional e mais cultural, já que apesar do avanço de seus procedimentos, nas rotinas individuais os valores que continuam sendo reforçados são os autoritários, como o de resolver os problemas diretamente e, em especial, fazer justiça com as próprias mãos.

Com vistas a apresentar um arcabouço analítico que permitisse examinar quais dos dois argumentos parece apresentar melhores contribuições para o caso brasileiro, os dados da Pesquisa Nacional de Vitimização (PNV) foram escrutinados em sua parte de agressões verbais e físicas cometidas pela população em geral e pela Polícia Militar em especial. Se a democracia que se institucionalizou no Brasil foi a de procedimentos (em detrimento da cultural) e se os valores que estruturam a sociabilidade entre os indivíduos são violentos (em detrimento do respeito aos direitos humanos e civis) a população como um todo deve lançar mão de agressões diversas para a resolução de suas controvérsias e esse padrão de 
conduta deve estar refletido no modus operandi da principal instituição responsável pela proteção imediata dos cidadãos: a polícia militar.

A análise de dados demonstrou que a violência pode ser considerada em parte como atitude cotidiana da população brasileira. Do total de entrevistados, $11,1 \%$ sofreram agressão verbal e 2,7\% sofreram agressão física. Caso o sistema de crenças, valores e atitudes dos brasileiros tivesse como eixo estruturante somente a violência, os percentuais encontrados seriam substantivamente maiores, mas a presença de uma parcela considerável de vítimas indica a sua recorrência na rotina de sociabilidade.

Os perfis das vítimas de agressões - verbais e físicas - corroborou que esse tipo de conduta compõe os valores de uma determinada classe social, composta por indivíduos jovens, de cor escura, com baixa renda e baixa escolaridade. Por ser parte do sistema cultural de uma classe social, esse tipo de violência não faz distinção entre os sexos, vitimizando homens e mulheres em proporções bastante similares.

Partindo do pressuposto de que a violência praticada pelos indivíduos em suas rotinas termina por encontrar ressonância no padrão de operação das instituições estatais, foram analisados ainda os dados de agressão verbal e física em que o perpetrador foi um policial militar. Desde o cálculo dos percentuais totais ficou evidente que a violência engendrada por essa organização possui uma lógica bastante diferenciada daquela que compõe o estilo de vida das camadas mais populares.

Ao contrário do apurado na população como um todo, a Polícia Militar provoca mais casos de agressão física do que os próprios indivíduos - 4\% PM contra 2,7\% geral. Enquanto na agressão verbal o quadro é diferente - 6,7\% PM contra $11 \%$ geral. Ou seja, se a violência praticada pela PM fosse, de fato, reflexo da violência que estrutura as regras de sociabilidade entre os próprios indivíduos, os percentuais de ambos os casos deveriam ser semelhantes e os percentuais de vítimas ocasionadas pela PM não poderiam ser maiores do que os percentuais de vítimas em geral.

Os perfis de vítimas das agressões policiais deixa evidente que a violência policial não é algo espraiado pela sociedade como um todo, sendo dirigida à classe cuja violência integra o seu estilo de vida. São os mais jovens, de cor escura, com baixa escolaridade e renda os que mais sofrem com os excessos dos policiais militares.

Todavia, ao contrário do que ocorre com as agressões em geral, as agressões policiais têm um sexo preferencial: o masculino, o que reforça a ideia de que o padrão de conduta agressivo da Polícia Militar não é reflexo da cultura de 
Quando o Estado é o perpetrador da violência: Uma análise das vitimizações ocasionadas pela Polícia Militar

classe e sim de uma cultura institucional policial, que focaliza os homens pobres de cor escura como objeto de ação preferencial. ${ }^{10}$

O arcabouço empírico deste trabalho aponta não para o reforço de um dos dois modelos apresentados para a análise do caso brasileiro, mas para a importância de conexão entre ambos. As agressões verbais e físicas compõem o sistema de crenças, valores e atitudes dos jovens de classe baixa, a despeito da institucionalização dos procedimentos democráticos, em especial, os relativos à dimensão política do regime. Por outro lado, quando se observa o padrão de operação das organizações policiais, é evidente que a violência engendrada por essa agência não pode ser entendida como mera ressonância daquela que estrutura a sociabilidade dos jovens de classe baixa. A violência praticada pela Polícia Militar é muito mais física do que verbal, denotando uma certa releitura dos paradigmas culturais brasileiros dentro de uma perspectiva institucional.

Em que pese o avanço dos procedimentos democráticos no Brasil, o fato de a violência ainda compor o estilo de vida de uma determinada classe social e, de maneira distinta, o padrão de operação de uma agência estatal, reforçando a ideia de que a violência estrutura o sistema de crenças, valores e atitudes da cidadania, corroborando o paradoxo brasileiro. Exatamente por isso, assistimos todos os dias a um crescimento da ideia de democracia, ainda que a sociabilidade violenta seja parte do pão nosso de cada dia da população de baixa renda, escolaridade e de cor de pele escura.

Referências bibliográficas:

ARIAS, Enrique Desmond; GOLDSTEIN, Daniel. Violent pluralism: understanding the new democracies of Latin America. Duke University Press, 2010.

BEATO, Cláudio C. Crime e cidades. Editora UFMG, 2012.

BONNER, Michelle D. Violence, Policing, and Citizen (In) Security. Latin American Research Review, v. 49, n. 1, p. 261-269, 2014.

CANO, Ignacio. Os Donos do Morro: Uma Avaliação Exploratória do Impacto das Unidades de Polícia Pacificadora (UPPs) no Rio de Janeiro. Rio de Janeiro, LAV/UERJ e Fórum Brasileiro de Segurança Pública, 2012.

CANO, Ignacio. Políticas de segurança pública no Brasil: tentativas de modernização e democratização versus a guerra contra o crime. Sur. Revista Internacional de Direitos Humanos, v. 3, n. 5, p. 136-155, 2006.

COELHO, Edmundo Campos. Sobre sociólogos, pobreza e crime. Revista de Ciências Sociais, v. 23, n. 3, 1980.

\footnotetext{
${ }^{10}$ Ver Ramos et al (2005) sobre como o estereótipo de "elemento suspeito" guia a ação da Polícia Militar do Estado do Rio de Janeiro.
} 
FBSP. Anuário do Fórum Brasileiro de Segurança Pública, ano de 2012. Disponível em: < http://www2.forumseguranca.org.br>. acesso em 10 de agosto de 2013

FRENCH, Jan Hoffman. Rethinking Police Violence in Brazil: Unmasking the Public Secret of Race. Latin American Politics and Society, v. 55, n. 4, p. 161181, 2013.

HOLSTON, James; CALDEIRA, Teresa. Democracy, law, and violence: disjunctions of Brazilian citizenship. Fault lines of democracy in post-transition Latin America, p. 263-96, 1998.

HUMAN RIGHTS WATCH. Lethal force: police violence and public security in Rio de Janeiro and São Paulo. Nova York: HRW, 2009.

LEMGRUBER, Julita. Violência, omissão e insegurança pública: o pão nosso de cada dia. Rio de Janeiro: Academia Brasileira de Ciências, 2004.

LIMA, Renato; BORGES, Doriam. Estatísticas Criminais no Brasil. In: Renato Sérgio de Lima; José Luiz Ratton; Rodrigo G. de Azevedo. (Org.). Crime, Polícia e Justiça no Brasil. 1ed.São Paulo: Editora Contexto, 2014, v. 1, p. 213-226.

MACHADO DA SILVA, Luiz Antônio. Vida sob cerco: violência e rotina nas favelas do Rio de Janeiro. Nova Fronteira, 2008.

MISSE, Michel. Crime, sujeito e sujeição criminal: aspectos de uma contribuição analítica sobre a categoria" bandido. Lua Nova, v. 79, p. 15-38, 2010.

MITCHELL, Michael J.; WOOD, Charles H. Ironies of citizenship: skin color, police brutality, and the challenge to democracy in Brazil. Social Forces, v. 77, n. 3, p. 1001-1020, 1999.

O'DONNELL, Guillermo. Human development, human rights, and democracy.The quality of democracy: Theory and applications, p. 9-92, 2004.

PERALVA, Angelina. Violência e democracia: o paradoxo brasileiro. Paz e Terra, 2000.

PRATES, Marco Aurélio Spyer et al. O estilo brasileiro de administrar: sumário de um modelo de ação cultural com base na gestão empresarial.Cultura organizacional e cultura brasileira. São Paulo, Atlas, 1997.

RAMOS, Silvia et al. Elemento suspeito: abordagem policial e discriminação na cidade do Rio de Janeiro. Editora Record, 2005.

RIBEIRO, Ludmila; MACHADO, Igor. A Emenda Constitucional nº45/2004 e a questão do acesso à justiça dez anos depois. In: Cardenos de Justiça. Brasília: Ministério da Justiça / Secretaria de Reforma do Judiciário, 2014 (no prelo).

WAISELFISZ, Julio Jacobo. Mapa da violência: homicídios e juventude no Brasil. Rio de Janeiro: FLACSO, 2013. 